\title{
Assessing Global Organ Donation Policies: Opt-In vs Opt-Out
}

\author{
Harriet Rosanne Etheredge (iD) ${ }^{1,2}$ \\ 'Wits Donald Gordon Medical Centre, \\ School of Clinical Medicine, University of \\ the Witwatersrand, Johannesburg, South \\ Africa; ${ }^{2}$ Steve Biko Centre for Bioethics, \\ School of Clinical Medicine, University of \\ the Witwatersrand, Johannesburg, South \\ Africa
}

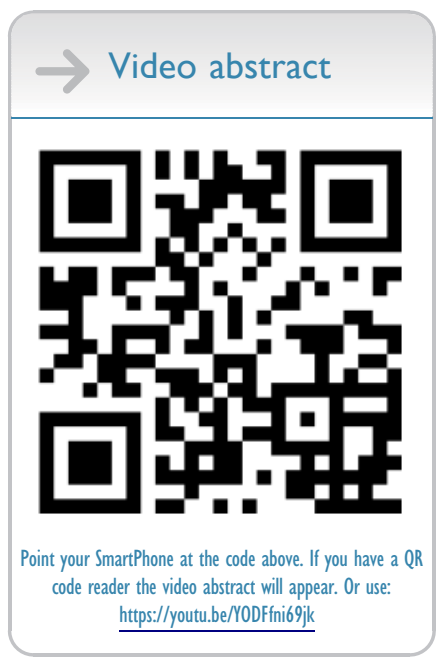

Correspondence: Harriet Rosanne Etheredge

Wits Donald Gordon Medical Centre, Ist Floor, Max Price Building, 27 Eton Road, Parktown, Johannesburg, 2193, South Africa

Tel +27 I I 3566395

Email harriet.etheredge@mediclinic.co.za
Abstract: This paper argues that there is little difference between opt-in and opt-out organ donation systems for increasing donor numbers when used in isolation. Independently diverting to an opt-out system confers no obvious advantage and can harm efforts to bolster donations. Rather, it is essential to address barriers to organ donation on several levels along with a switch in system. Moreover, for many countries, it may be more beneficial to adequately capacitate the donation system already in place, rather than entertain a significant change with its attendant resource requirements. For decades, the international transplant community has been involved in vigorous debate as to the merits of moving from default opt-in systems to opt-out policies to grow organ donor numbers and better meet the everincreasing demand for lifesaving transplants. Opt-out is certainly en vogue, with Wales, England and Nova Scotia recently switching over, Scotland due to become opt-out in March 2021 and Northern Ireland and Canada seriously considering a similar move. Thanks to several countries making the switch from opt-in to opt-out over the last 20-30 years, there are sets of robust longitudinal data that aid in analysing the efficacy of donation systems. However, these data are often contradictory and largely inconclusive, suggesting other factors may be in play. This paper reviews some emerging trends in opt-in versus opt-out organ donation policies and considers recent data that elucidates some of the main contentions across each. Ethical frameworks underpinning donation systems, such as informed consent, trust and transparency, are discussed in detail. Substantial time is also devoted to opt-in vs opt-out systems in developing countries, which tend to be excluded from many analyses, and where the challenges faced are magnified by socio-economic constraints. This constitutes a major gap in recently published literature, as developing countries often lag far behind their developed counterparts in donor and transplant numbers.

Keywords: organ donation, opt-in, opt-out, consent, transparency, developing countries

\section{Plain Language Summary}

Organ donation is known to save lives. Worldwide, one of the main challenges in organ donation is that the demand for organs far exceeds their supply. This means we lose many lives each year, because there are not enough organs for everyone. This situation compels countries to consider different systems for increasing organ donor numbers.

Many have argued that switching from an "opt-in" to an "opt-out" policy for organ donation will greatly increase donor numbers. An opt-out policy presumes that every person in a country is willing to be an organ donor after they die. Those who are not willing, need to make this clear, usually be signing an official statement to this effect.

Often, people's first reaction to opt-out is that it sounds brilliant because there are millions of people in each country, and they would all be donors. However, changing to an opt-out system is not nearly this simple, or this effective. 
This paper compares recent data from opt-in and opt-out countries, showing that opt-out systems do not have all the benefits we might hope. Rather, the key to increasing organ donor numbers is carefully addressing "barriers to donation" as they occur in each country, as well as ensuring that organ donation engenders public trust, and is transparent and accountable to the patients and population it serves.

\section{Introduction}

For decades, the international transplant community has been involved in vigorous debate as to the merits of moving from default opt-in systems to opt-out policies to bolster organ donor numbers, and better meet the everincreasing demand for lifesaving transplants. Opt-out is certainly en vogue, with Wales, England and Nova Scotia recently switching over, Scotland due to become opt-out in March 2021 and Northern Ireland and Canada seriously considering a similar move.

Why is this debate so long-lived? It is because organ transplantation is a life-saving procedure indicated in many individuals with end-stage organ failure. Although dialysis is available to patients in end-stage renal failure, transplantation is by far the best and cheapest option for them. ${ }^{1}$ There is no widely used "bridge to transplant" such as dialysis available for patients in liver, cardiac and lung failure. Whilst mechanical circulatory devices may delay the need for heart transplantation, and extracorporeal membrane oxygenation (ECMO) functions as a bridge to lung transplantation in acute care, these modalities are extremely expensive and their use remains limited in transplant settings. Thus, organ transplantation is a field of medicine with extremely high stakes. It represents the final chance at life, for patients the world over. Without a transplant, these patients will demise. Within this high stakes arena, a fundamental challenge in transplant is that the supply of donor organs generally falls far short of demand for them. Consequently, the transplant community should be (and is) continuously looking at mechanisms to boost organ supply. These include utilising expanded criteria donor organs, utilising living donors more widely ${ }^{2}$ and changing systems to increase deceased donor numbers - which is the topic of this paper.

\section{Common Definitions and Abbreviations Types of Donation}

Deceased donation - Organ donation by an individual who has been certified as deceased according to either brain steam or circulatory criteria. "Organ donation" in this article refers specifically to deceased donation - unless stated otherwise.

Living donation - Organ donation from a living donor. Generally limited to renal and hepatic donation. Any reference to living donation in this article will be explicitly labelled as such.

Organ transplantation - This involves the surgical procedure to implant organs from the donor (deceased or living) into the recipient. Maintaining the distinction between organ "donation" and "transplantation" is vital, as not all donations result in actual transplants. In this paper, "organ transplantation" refers to the surgical process and 'transplant numbers' refer to the number of transplants performed, not the number of donations that have taken place.

Organ procurement - This is the process where the implementation of integrated systems across a country result in organs being donated for transplantation. The pointy end of this process involves a procurement transplant coordinator seeking consent to organ donation from a deceased individuals family.

\section{Transplant Systems}

Opt-out - A donation policy that presumes all individuals residing in a country/state to be a willing deceased organ donor unless they specifically "opt-out" of doing so. Also known as "presumed consent". Opting-out would require individuals to state their preference against deceased organ donation whilst alive. Such preference is often recorded in a national opt-out register.

Opt-in - A donation policy that requires individuals to manifestly express their preferences for being a deceased organ donor. It is the opposite of opt-out, because no one is presumed to be a willing donor unless they make an express statement regarding their preference for deceased donation. Also known as an "express consent" policy.

\section{Consent Mechanisms}

Hard consent - Hard consent policies emphasise the preferences of the individual, as stated in life, as binding, and effectively there is no role for the family in consenting to donation, or authorising donation. In a hard opt-in system, a preference for organ donation would need to be stated by the individual in question. In a hard opt-out system, the individual would have needed to opt-out during their lifetime to avoid becoming a donor. 
Soft-consent - Soft consent policies involve the potential donor's family, whether the country is opt-in or optout. In opt-in countries, families can be approached to consent to donation where the wishes of a loved-one have never been explicitly stated; or to legally authorise donation where they have. In an opt-out scenario, families are approached to "authorise" the default of donation in terms of the status quo. This gives the family an opportunity to ensure the potential donor's preferences are regarded, in the event that they have not opted out for whatever reason.

Mandated choice - Mandated choice is an organ donation policy that obliges individuals in a country/ state to decide about their organ donation preferences whilst still alive and have these recorded. Mandated choices are often made when applying for a driving licence or other official documentation. In an opt-in system, the "choice" would involve providing express consent to deceased organ donation. In an opt-out system, the choice would involve explicitly opting-out of organ donation.

\section{Decision-Making and Deceased Persons}

Deceased organ donation, at its very foundations, hinges on the premise that when people die, their healthy organs can be implanted into others and will resume normal functioning. Organ donation dwells in the space between life and death, adding to its complexities and society's often emotive response to it. Generally, deceased individuals are no longer considered "legal subjects' and as such they don't have legal rights in the way that living human beings do. It may follow, then, that organs could be removed from all deceased individuals regardless of preference stated during life. However, the enduring maxim worldwide is that family members have certain rights when it comes to disposing of the remains of a next-ofkin, and that the deceased are entitled to posthumous dignity, regardless of jurisdiction. ${ }^{3}$ Moreover, courts will generally defer to the wishes of the deceased, as expressed during life, regarding disposition of their remains. ${ }^{4}$ That said, these rights are not absolute, and the remains of a deceased may be retained by authorities in certain circumstances. ${ }^{4}$

The question of who decides what happens to a deceased body is almost always defined by the legal framework of the country where the deceased has lived and/ or demised. This has implications for organ donation, and makes the distinction between opt-in and opt-out less clear. Firstly, legal frameworks will dictate the extent to which an individual's preferences for organ donation as stated in life are honoured, or to which these could be overruled by surviving next-of-kin. Secondly, the legal framework will mediate the extremity of organ donation policies in a country, with "organ conscription" perhaps the most drastic of these. ${ }^{5}$ Thirdly, it will direct the explicit content of organ donation policies, and determine what type of consent is needed, and whom can provide it. Ultimately, there is no universally accepted standard for human remains ${ }^{6}$ - whether they can still be acceded any "rights", what there "rights" look like and who can give them effect.

Whilst this complicates discussions about organ donation policies, it does not nullify them. Rather it suggests that careful consideration of legal framework and societal mores about death is also required, and policies should be responsive to these.

\section{Overview of Main Arguments}

Proponents of opt-out contend that these systems result in higher deceased donor rates, because they presume every individual in a country to be a willing organ donor unless they specifically opt-out of the process (or a variation thereof). ${ }^{7}$ Furthermore, it is argued that opt-out systems overcome many traditional barriers to deceased organ donation - such as perceived religious or socio-cultural preclusions, lack of education or transplant awareness and challenges in communicating with families who are grieving a loved one. ${ }^{8}$ Opt-out supposedly does this by changing the national "default" from non-donation to donation, which has implications for the collective psyche of a country. ${ }^{9}$

Contextualised more widely, caution is often advised when considering such a move. Firstly, there is an issue with the very presumption of willingness to donate organs. An explicit unwillingness to become deceased organ donors has been detailed across several publications and sectors of society, internationally. ${ }^{10}$ Simply changing the default presumption to one of donation and hence negating the requirement to approach a deceased's family and seek their consent - does not imply that they will now be willing to donate, or that there has been a fundamental shift in these overarching preferences. ${ }^{10}$ Hence, the acceptability of such a policy 
in the societal sense needs to be carefully interrogated and sensitively analysed.

Secondly, opt-out systems require extensive government buy-in and infrastructural investment for their success. In many countries, especially in Africa, this seems lacking. ${ }^{11,12}$ Moreover, careless or heavy-handed implementation of an opt-out policy is implicated in diminishing trust in healthcare systems ${ }^{9}$ and is construed as contrary to some human rights in certain settings. Additionally, the power of opt-out to overcome barriers to organ donation as they manifest when seeking family consent at the bedside may be consistently overstated. ${ }^{5}$ In any country where informed consent is a fundamental premise of healthcare provision, and families have rights regarding the remains of deceased relatives, next-of-kin would still need to be approached to authorise organ donation in an opt-out system. Hence, these barriers to organ donation may not fall away as readily as many might like.

Thanks to several countries making the switch from opt-in to opt-out over the last 20-30 years, ${ }^{7}$ sets of robust longitudinal data have been generated. These aid in analysing the efficacy of our donation systems. However, these data are often contradictory and largely inconclusive. Most recent academic publications in this domain conclude that changes in donor numbers cannot be attributed to the organ donation system alone. ${ }^{13-17}$ They contend that other factors at multiple health system and population levels require consideration.

This paper argues that there is little difference between the opt-in and opt-out organ donation systems, and that successfully increasing donor numbers involves a multi-faceted approach. It reviews some emerging trends in opt-in versus opt-out organ donation policies, and considers recent data that may further elucidate some of the main contentions across each. Ethical frameworks underpinning donation systems, such as informed consent, trust and transparency are discussed in detail. Substantial time is also devoted to opt-in vs opt-out systems in developing countries, which tend to be excluded from many analyses, and where the challenges faced are often magnified by socio-economic constraints especially on the African continent. This constitutes a major gap in recently published literature, as developing countries often lag far behind their developed counterparts in donor and transplant numbers.

\section{The Current State of Play - Recent Statistics and Analysis of Primary Trends Across Selected Countries}

A contemporary, thorough comparison of organ donation (deceased and living) and transplant rates across 18 Organisation for Economic Cooperation and Development (OECD) countries by Arshad et al provides critical outcome analysis of opt-in vs opt-out donation policies. ${ }^{13}$ The paper concludes that there is no significant difference in the number of organ donors across opt-out (20.3 PMP) and opt-in (15.4 PMP) countries. However, they note a significant difference where opt-in countries had more living donors per million population (15.7 PMP) than opt-out countries (4.8 PMP). The authors note that the cause of this discrepancy in living donor numbers can only be speculated. ${ }^{13}$

Arshad et al carefully detail the limitations of their analysis, and state that their findings support other sources asserting that there is no "magic bullet" for increasing donation rates. They conclude that the deceptively simple task of switching from opt-in to opt-out is unlikely to have the impact on donor numbers that many early proponents of opt-out had advocated. ${ }^{13}$ Effectively, addressing donor shortages requires a multi-faceted approach considering barriers to organ donation as they manifest across a society. These range from unfavourable personal views or individual experiences, to collective religious or social-cultural preclusions, to the actions of lawmakers, politicians and others who influence public thought and the healthcare workers on the ground, who bring their own perceptions to bear on the organ donation process - yet are integral to its success given they are on the front lines. ${ }^{18}$

The analysis presented by Arshad et al has clinical implications for organ donation, and these warrant exploration. The clinical reality is that one deceased organ donor may save up to seven lives. According to Arshad et al, opt-in countries lose out on approximately 5 deceased donors PMP annually as compared to their optout counterparts. Clinically, therefore, in a hypothetical population of one million people, this translates into a maximum of 35 additional lifesaving procedures per year. In a population of 100 million people, an additional 3500 transplants could take place. And so on. This number is relevant to patients at the end of the process, who have end-stage organ failure and are awaiting a transplant to save their life. 
These clinical implications need to be contextualised within significant findings of lower living donor rates in opt-out countries than their opt-in neighbours. ${ }^{13}$ For clinical purposes looking at total transplant numbers, rather than donor numbers, may provide some resolution. Overall solid organ transplantation numbers across the OECD countries in this analysis were 63.6 transplants PMP in opt-out countries and 61.7 transplants PMP in opt-in countries. These figures speak specifically to the number of lives saved. Based on this analysis, it may be reasonable to conclude that there is little difference between opt-in and opt-out systems. Where opt-in systems lose deceased donors, they gain living donors - and the resultant transplant numbers ultimately average out across both.

Arshad et $\mathrm{a}^{13}$ is widely contradicted in other publications. A recent, PROSPERO-registered systematic review considered differences in transplant numbers between optin and opt-out countries and concluded that opt-out countries boasted demonstrably greater deceased donor rates than opt-in countries. ${ }^{5}$ The authors extrapolated these data to the United States of America (USA), contending that the country could enjoy an additional 4,753-17,201 transplants annually if an opt-out system were introduced. Interestingly, if any country were to benefit fully from an opt-out system, it may be the USA, thanks to the infrastructure for organ donation and transplantation that is already in place. This includes nationwide coordination of transplantation activities through UNOS and the OPTN, the means to maintain detailed donor registers and the obligation on transplant centres to publish their outcomes as a form of quality control and accreditation. ${ }^{19,20}$

The debate becomes more opaque when considering the organ donation and procurement system in Spain. Spain is a success story, with the highest number of deceased donors PMP internationally (49.6 in 2019, compared to 36.8 in the USA for 2019). ${ }^{21}$ However, appraisal of organ donation in Spain is far from unequivocal in demonstrating the success of opt-out.

Spain's achievements in the transplant arena are often attributed to its "opt-out" policy, but the organ donation system in Spain is not this simple, and Spanish transplant experts themselves do not consider Spain to be an "optout" country. ${ }^{14}$ Spain does not have an opt-out register for those who prefer not to donate, and families are always approached to authorise organ donation. These factors contradict some of the main premises of opt-out donation, rather negating its impact. It was only ten years after Spain introduced its "opt-out" policy that deceased donor numbers started to rise, and the increase is attributed to several initiatives mainly at hospital level. The Spanish government established a national transplant network across all hospitals, and invested substantially in facilitating the early identification of potential donors by capacitating hospital staff specifically for this purpose. A vast transplant coordinator network, specially trained in requesting organ donation, approaches family members. There has been a drive to promote donation after circulatory death, as well as the use of expanded criteria allografts to increase organ utilisation. These factors are thought to have had much more impact on deceased donation rates than the overall organ procurement system. ${ }^{14}$

The case of Spain also teaches us about the importance of nuance in assessing organ donation systems, and the potential danger of labelling a system as one thing, or another. Spain conforms to the traditional premises of neither organ donation system - but perhaps is more similar to opt-in, than opt-out. Effectively, this distinction between systems does not seem as important as the careful layers of legislation, public education, healthcare infrastructure and human resourcing that have been instituted in Spain. Barriers to transplant were identified within the Spanish context, and systematically addressed. Although relativism is to be discouraged, a multifocal approach that is specifically tailored the transplant context of a country, and can respond to change, appears to have significant benefits. ${ }^{22,23}$

The Spanish experience, with its commitment to investment and innovation, is somewhat mirrored by transplant policies and the evolution of organ donor legislation in Singapore. Singapore is a wealthy country, with significant religious diversity. Specifically, there is a large sector of the Singaporean population that practices Islam. Although it is by no means a universality, it is often stated that the Islamic religion has certain preclusions against deceased organ donation. The reasons for this include concerns about the sanctity of the body and sometimes contradictory positions taken in Islamic scripture and by some Islamic religious leaders. ${ }^{10,24,25}$ The Singaporean organ donation system is telling for its flexibility, and the way in which it has had to adapt to balance accommodating the religious practices of some of its population with the ever-increasing demand for donor organs. The elasticity of organ donation policies in Singapore suggests that there is substantial governmental involvement and interest 
in providing a comprehensive and responsive transplant service.

An opt-in country from 1973, Singapore enacted optout legislation under the Human Organ Transplant Act (HOTA) in 1987. Initially, this policy applied only to kidney donation (at that time about 4.7 kidney transplants were taking place in Singapore annually (absolute numbers)), and all Islamic individuals were automatically excluded. Non-Islamic individuals of sound mind and between the ages of 21 and 60 who had been certified as "accidental death" were presumed to be kidney donors unless they had explicitly opted out. By 2004, Singapore had seen deceased donor renal transplant rise to an average of 40.8 per annum (absolute number). There was still a significant donor shortfall, so HOTA was amended to include heart, liver (and cornea) donation and extended to potential donors who had non-accidental causes of death. HOTA was amended once again in 2008 to include the Islamic community and subsequently in 2009 to extend the upper age limit for presumed consent and add additional safeguards. ${ }^{26}$ Currently, Singapore has a deceased donor renal transplant rate of 40 per annum (absolute numbers), so there has been little increase in this figure since $2004^{21}$ and it is concluded that further measures are needed to improve this.

Through this review of recent literature, several trends start to emerge that define successful donation policies (Table 1). Firstly, there is no numerical consensus on which donation system (opt-in or opt-out) is superior. Secondly, successful system changes are accompanied by complementary interventions at different levels of society and the health system. Thirdly, legislative adaptation and flexibility is essential.

\section{Transparency and Trust}

As a medical field, organ transplantation is imbued with significant emotion. It is often a time of immense grief for the families of potential donors, who must make decisions in the immediate aftermath of personal tragedy. Conversely, research suggests that recipients and their

Table I Country Overview (Alphabetical Order)

\begin{tabular}{|c|c|c|c|}
\hline Country & $\begin{array}{l}\text { Deceased } \\
\text { Donors PMP }\end{array}$ & System & Efficacy of Changing to Opt-Out \\
\hline \multirow[t]{2}{*}{ Argentina } & \multirow[t]{2}{*}{19.6} & Hybrid from 2005 & The hybrid system resulted in a dramatic increase in deceased donor rates. \\
\hline & & Opt-out from 2018 & The move to a more conventional opt-out is too recent to be thoroughly evaluated. \\
\hline Brazil & 18.10 & $\begin{array}{l}\text { Opt-out from } \\
1997-1998\end{array}$ & $\begin{array}{l}\text { Opt-out implemented in a rushed fashion, and not well received by the public or health } \\
\text { professionals. Abolished in } 1998 \text {. }\end{array}$ \\
\hline Chile & 10.4 & Opt-out & $\begin{array}{l}\text { Initially, the opt-out system resulted in a much lower donation rate, and mass opt-outs } \\
\text { were recorded. The deceased donor rate has subsequently risen as Chile now requires a } \\
\text { much more explicit opt-out, and the reciprocity principle has been introduced. }\end{array}$ \\
\hline Columbia & 8.4 & Opt-out & $\begin{array}{l}\text { The switch was recent, and at present seems to have had not overall effect on deceased } \\
\text { donor numbers. }\end{array}$ \\
\hline Malaysia & 0.53 & Opt-in & NA \\
\hline Singapore & 6.6 & Opt-out & $\begin{array}{l}\text { The switch to opt-out initially resulted in an increased in deceased donor rates, however } \\
\text { this has subsequently stagnated in spite of substantial legal amendments. It is concluded } \\
\text { that further work is needed to increase donor rates. }\end{array}$ \\
\hline Spain & 49.00 & $\begin{array}{l}\text { Hybrid/neither clearly } \\
\text { opt-in or opt-out }\end{array}$ & $\begin{array}{l}\text { Effective, especially in its investment into resources to engage in donor identification and } \\
\text { approaching families at clinical level. }\end{array}$ \\
\hline $\begin{array}{l}\text { South } \\
\text { Africa }\end{array}$ & $1.29(2016)$ & Opt-in & NA \\
\hline Thailand & 3.66 & Opt-in & NA \\
\hline USA & 36.88 & Opt-in & NA \\
\hline
\end{tabular}

Notes: This table overviews the deceased organ donation systems of the different countries addressed in this article. It presents a brief summary of the success, or otherwise, of these transitions. 
networks experience both elation when an organ becomes available, and extreme guilt related to the necessity of another dying, for them to live. ${ }^{27}$ Additionally, organ transplantation involves the transfer of body parts from deceased persons, and is often (wrongly) conflated with "darker" practices. ${ }^{18}$

Distrust of the healthcare system is an established barrier to organ donation - regardless of donor policy. Without trust, large-scale unwillingness to consider donation will abide, and increases in donor numbers are unlikely. On a theoretical level, a great deal has been written about trust and organ donation. ${ }^{24,28-30}$ Perverse financial incentives, perceptions of economic gain, reports of transplant practices favouring the wealthy, manipulation of transplant systems in favour of certain patients and unethical procurement practices have all directly diminished public trust in organ transplantation.

For instance, in South Africa, a "Cash for Kidneys" organ trafficking case broke in 2002. Poverty-stricken Brazilian "donors" (vendors) were flown to the country, their kidneys removed and transplanted into wealthy individuals, primarily of Israeli origin. These individuals made payment to the "donor" (vendor), as well as brokerage costs and surgical costs. A dramatic decrease in donor numbers in South Africa ensued. ${ }^{18,31}$

In another example, in 2013, it was reported that German transplant surgeons had manipulated the liver transplant system in favour of certain patients by falsifying their medical records, and exaggerating the severity of these patients' illness so that they would receive priority on the waiting list. ${ }^{32}$ This resulted in the diversion of donor livers from those who were critically ill, to other individuals in less-critical conditions. The scandal involved extensive deception of both patients and the general public in Germany, and a resultant decrease in donor rates was noted in Germany, with possible implications for the European Union in its entirety. ${ }^{32}$

More recently, unethical organ procurement practices in China have perpetuated public distrust in organ donation to the extent that many academic journals publishing research in this field have amended their ethics and disclosure policies. ${ }^{33}$ For several years, organs from executed prisoners have been used for transplant purposes in some parts of China without informed consent. Chinese authorities stated that this practice would be phased out, but as of January 2014, it was reported to continue unabated. ${ }^{34}$ Prisoners are regarded as a vulnerable group, in the sense that their institutionalised status may diminish their autonomy and inhibit their ability to make fully informed decisions. ${ }^{35}$ Presently, when publishing papers that involve organ transplantation, many academic journals now require authors to explicitly state that no organs from executed prisoners were utilised in the research process, in the main body of the text. This is in an effort to bolster public trust.

Sensationalised reports of organ donation and transplant in the mass media or on social media are often a catalyst for distrust. Anything published in the milieu of organ trafficking, grave robbing, muti murders and the like is bound to diminish trust. Some of these reports are true, and there is a strong argument to be made for publishing information that is in the public interest. However, organ donation is often portrayed with scant regard for the facts.

\section{Regaining Public Trust}

There are several measures that societies can take to bolster trust in their organ donation and transplant systems. One of the most important is to engender transparency into every facet of the transplant process. It is essential that data on donor numbers, transplant numbers and transplant outcomes are made publicly available, and that there is a system in place to audit transplant programmes and take remedial action should deficiencies be identified. ${ }^{36,37}$ Many countries take this further, and transplant centres are obliged to report their data annually. Failure to do so can result in a centre losing its clearance to perform organ transplantation.

How do transparency and trust impact on opt-in or optout policies? A recent expert panel deemed opt-out policies to be more widely associated with deception, manipulation and restricted freedom of choice than opt-in policies. ${ }^{9}$ Moreover, the effort associated with opting-out was considered more onerous than opting-in. This means that a failure to opt-out does not imply that the person was inclined to the default and willing to donate - rather that they simply did not have the time to opt-out at present.

These observations should give any country considering a move to opt-out pause for thought. The implementation of any system that threatens to provoke doubts about organ donation would necessarily need to set a high bar for public trust and transparency, or the move might backfire.

\section{Informed Consent - Conversations with Families at the Bedside}

Proponents of the opt-out system often suggest that one of its main advantages is overcoming barriers related to 
gaining consent from potential donor families at the bedside. These barriers are not insignificant. Health professionals often feel underequipped to have difficult conversations with families, or unsupported by their institutions or governments. Families may have personal contextual objections to organ donation, may not be familiar with the wishes of their loved one or may be unable to fully comprehend what is being asked of them at a time of grief. ${ }^{38}$ The USA utilises an opt-in system, and proves a useful exemplar of these barriers. It is estimated that $15-45 \%$ of deceased donors are lost during the consent process with families in the USA. ${ }^{5}$ This finding needs to be contextualised against overwhelming public support for organ donation, at $97.6 \% .{ }^{39}$ There is also a relatively high number of sign-ups to the organ donor registry in the USA, with $62.3 \%$ of individuals signing-up when applying for a driver's licence. ${ }^{39}$ If this is indicative of intention to donate, the fact that so many donors are lost at the family consent stage suggests that something is amiss. Overwhelming positive sentiment does not translate into actual, consented donations.

Would an opt-out system really overcome these challenges? By changing the default and creating an environment where donation is the norm - are families more willing to consent? Are they happy to have the wishes of a deceased loved-one presumed? The answer to this question seems to be a resounding "no" - as evidenced by outcries against hard opt-outs in countries like Brazil.

The story of Brazil is informative. It follows a similar trajectory to Singapore and Spain, in that Brazil's opt-out system had to be responsive to public sentiment and reservation expressed by healthcare providers, although for different reasons. Brazil introduced a "hard" opt-out system in 1997. The implication was that all individuals were considered willing deceased organ donors unless they opted-out. Families were not invited to authorise donations. This legislation caused outrage amongst the Brazilian public and it was ignored by health professionals, who continued the practice of seeking consent from families. In fact, Brazil's foray into opt-out was such a disaster that the legislation was abolished in its totality by the end of $1998 .{ }^{14}$

Hard opt-outs, where families are not approached to authorise donation, are a bitter pill for the public to swallow. They also diminish trust. Thus, it is likely that only soft opt-out systems will be generally acceptable to the international public and healthcare community. However, a soft opt-out system still requires family authorisation or consent, so it follows that the same challenges experienced by opt-in systems at the bedside, will manifest. A conversation still needs to take place, and if this is a make-orbreak point in the transplant process, enacting policies that do not directly address these barriers is something of a straw man.

In effect, both systems maintain the status quo if family consent is required. In opt-in systems, many families feel too unfamiliar with their loved-ones preferences to make a decision, unless there is a specific directive supporting organ donation or they have had a conversation about it. In opt-out, the absence of an entry in the opt-out register is not usually sufficiently demonstrative of a definitive wish to donate. Doubts emerge about whether the loved one know about the opt-out policy, understood it, or engaged with it - unless the family had a conversation about their donation preference in life. ${ }^{16}$

Though it may be an established workhorse, opt-out legislation is not the answer to overcoming barriers to donation at the bedside. As such most countries with high donor numbers have introduced measures to improve interaction with potential donor families during the process of seeking their consent or authorisation for donation. ${ }^{38}$ Many countries have also attempted to increase family consent rates by encouraging individuals to openly express their donation preferences whilst still alive.

\section{Opt-In, Opt-Out and Developing Countries}

Developing countries, especially those in Africa, are not often included in analysis of organ donation policies. One of the main reasons for this is that many developing countries, certainly those in Africa and some in Asia, have a very poor track record of making their data publicly available (Figure 1). ${ }^{40}$ Not only does this compromise transparency and trust, but it also excludes these countries from analyses that may benefit them. Furthermore, many developing countries face significant challenges in promoting access to organ donation and transplantation services. These include lack of governmental commitment to transplant, lack of public awareness and robust public education about transplant, general mistrust of biomedicine and negative perceptions of organ donation amongst both healthcare workers and the general public. ${ }^{1,12,18,41}$ The passage of legislation in some developing countries is slow. Law enforcement does not have the capacity to 


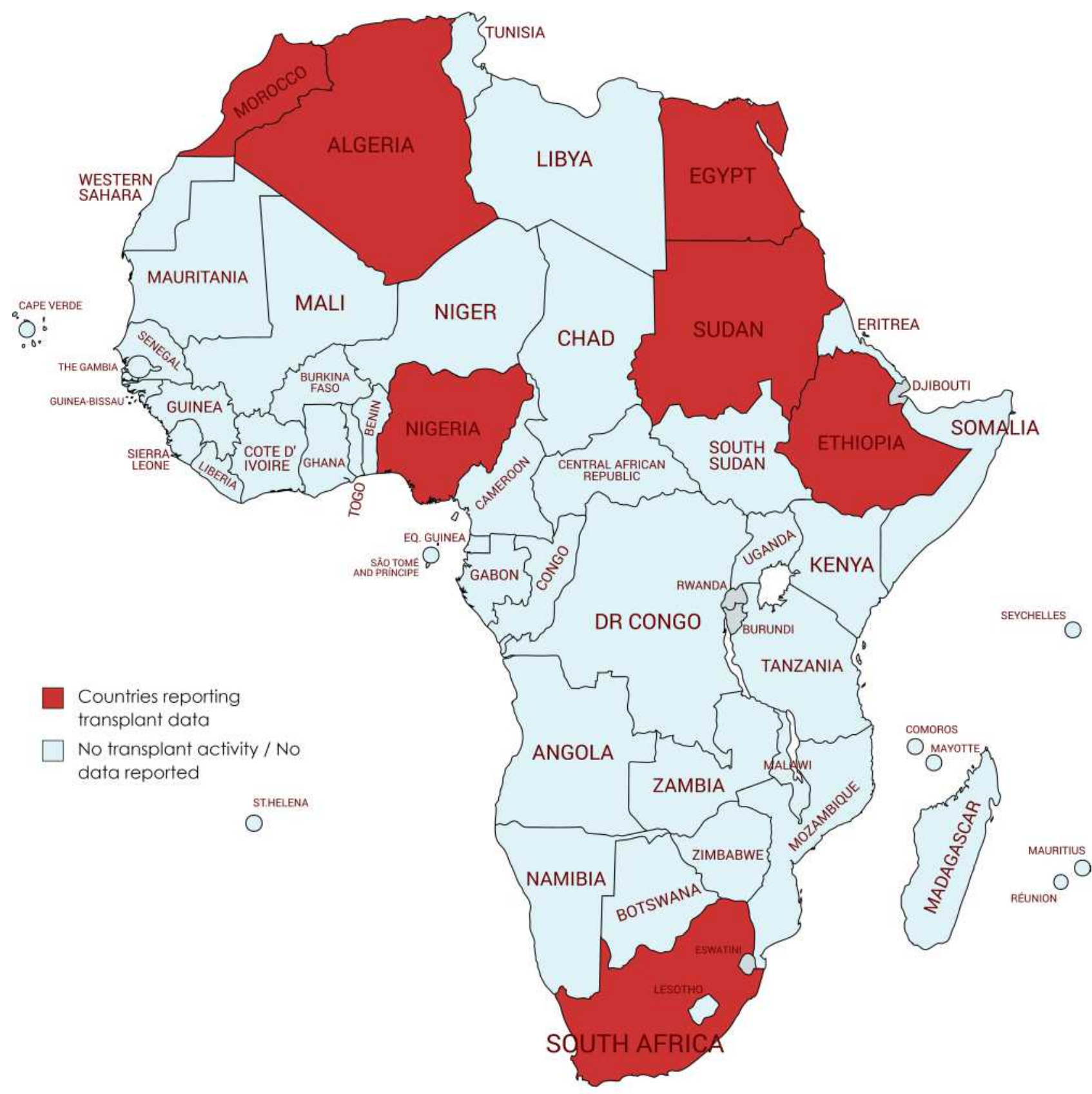

Created with mapchart.ne

Figure I This figure shows reported transplant activity across the continent of Africa (areas shaded in red). The blue areas either do not report transplant activity, or do not host any transplant activity. It is clear from this image, that organ transplantation is available to a very limited extent across the continent.

deal with transplant-related offences, leaving many developing countries vulnerable to organ trafficking. ${ }^{42}$ This further diminishes public trust and collective willingness to buy into organ donation.

Another important consideration when examining transplant systems in developing countries is differential access to healthcare services and the disparities this creates. Some developing countries, like South Africa, have a two-tier healthcare system. Private medical care affords wealthier residents much better access to transplant services than those who cannot afford it, and are obliged to seek treatment in the state sector. It has been argued that some transplant services for private patients in South Africa are on par with those enjoyed by individuals in 
several developed countries. Conversely, the provision of transplant services in the South African state sector is hindered by resource constraints. ${ }^{12}$ Analogous trends are seen in India, and many other countries where the two-tier healthcare provision model dominates. ${ }^{43}$ In a similar vein, worldwide, wealthier countries report higher donation and transplant rates than their developing counterparts, entrenching transplant as the purview of the wealthy, ${ }^{21}$ although some developing countries have worked hard to promote equality in access to these services.

Analysis of transplant provision in developing countries as a modality that may be primarily available to wealthy individuals is an important point of context for proceeding discussion, especially because this has generalised impact on public trust in transplant.

\section{Africa}

Opt-in policies remain the norm across Africa, and there is little evidence of African countries entering into critical, government-mandated analysis of their organ donation and transplant systems. This is worrying as the quadruple disease burden (communicable, non-communicable, infectious and maternal-neonatal) these countries face is escalating exponentially, and transplantation is the only option for many patients with end-stage disease across these categories. Although some transplant activity is taking place in the region it is hard to quantify (Figure 1); and a recent World Health Organisation report on transplant activity in Africa suggests a staggering lack of transparency across the continent. ${ }^{40}$ South Africa is cited as the only country regularly providing data to international transplant registries. The report also states that South Africa maintains its own transplant registries, but this is not accurate. There is no nationally accessible list of registered organ donors in South Africa, and there is no national transplant waiting list. ${ }^{11}$ The situation in South Africa is telling of the rest of the continent. As arguably the most developed African country, the overall lack of transplant cohesion in South Africa hints at the challenges that are facing other less-developed countries in the region.

Given these challenges, it is perhaps unsurprising that organ donation and transplantation is not a priority and, at best, limping along. This should be contextualised by considering health systems across Africa (often dysfunctional), ${ }^{44}$ governmental transplant policies (often opaque and confusing), ${ }^{41}$ transplant resources (often nonexistent) ${ }^{12}$ and public awareness about transplant (often lacking). A recent study from Nigeria proves a case-inpoint here. Amongst a sample of 850 Nigerian healthcare workers, $93.3 \%$ had heard of organ donation, however only $29.5 \%$ would consider donating organs themselves. A small percentage of participants (19.4\%) believed that organ transplantation was an effective health intervention and only $39.4 \%$ of respondents stated they would willingly advocate for organ donation at the bedside. ${ }^{45}$ As healthcare workers in developing countries, samples like this would be at the forefront of implementing any change to organ donation policies - and this analysis suggests that much work is needed to improve knowledge about and attitudes towards transplant before any overarching changes could be considered.

\section{Southeast Asia}

Some countries in Southeast Asia appear to have more transparent organ donation and transplant policies than those in Africa, and many Southeast Asian countries have invested significant time and money into bolstering their organ donation systems. ${ }^{26}$ Apart from Singapore and Brunei Darussalam, many Southeast Asian countries fall into middle- or low-income brackets, and they face the same health system, socio-cultural and economic challenges that affect their developing world counterparts. Additionally, the region is reputed as a hub for organ trafficking, which some countries have taken steps to address. $^{26}$

Thailand has a relatively low human development index, but has managed to achieve consistent transplant rates across its 26 transplant centres. It is opt-in, and has capacitated hospitals with transplant coordinators rather than change to an opt-out system. This resulted in a rise in donation and transplant rates, with the country reporting impressive transplant numbers - although reporting is voluntary. Thailand has achieved much in the transplant field, with substantial governmental support and public figure buy in.

Malaysia is considered a middle-income country, and it has also made significant investment into organ donation and transplantation. Several different national oversight bodies have been established, and there is careful coordination of transplant teams across each donor hospital. The country also has a national transplant waiting list. ${ }^{11}$ Between 2005 and 2014, transplant rates in Malaysia fell dramatically due to legislation against transplant tourism (which mainly came from China), and the Declaration of Istanbul. ${ }^{26}$ 


\section{Latin America}

The Latin-American region has been productive in addressing organ donor shortages, and exploring new mechanisms to increase transplant numbers. Many LatinAmerican countries have impressive track records in the field of organ transplantation, and report positive upward trends in their transplant rates.

Opt-out in Chile was introduced as part of a mandated choice system in 2010. All Chileans were required to decide about organ donation when applying for identification documentation and were able to opt-out at this point. In the year immediately following this move, there was a $29 \%$ decrease in deceased donor rates. Large-scale optouts were also recorded, with $37 \%$ of those renewing identity documents refusing donation and $54 \%$ of potential donor families doing likewise. Further exploration of these phenomena suggested that the Chilean population had been ill-informed about the opt-out policy, did not understand its implications and were under the impression that opt-out only facilitated transplantation for the wealthy. ${ }^{46}$ Subsequently, Chilean legislation was amended to require a notarised letter formally stating ones wish not to donate, rather than a mandated statement of preference. Chile also introduced a reciprocity principle for those who did not opt-out of donation, who are given priority if they need a transplant.

Given the incremental changes in legislation over time, it is hard to quantify what percentage of increased deceased donor numbers in Chile (54\% from 2010 to 2017 ) is due to the opt-out system or to the reciprocity principle. However, it is clear that legal elasticity is paramount, and this example highlights the importance of education and transparency if such a system is going to be successful.

Columbia is another Latin American country that has switched from an opt-in system to an opt-out system - in 2017. At the end of 2018, analysis of the Columbian donor registry showed that the change in policy had made no overall difference to kidney donation rates in the country. However, there was a small increase in donor numbers in geographical areas that traditionally had lower family consent rates. ${ }^{15}$ This may be due to changes in language used when requesting family authorisation for donation in an opt-out system - where conversations are framed by a default presumption of willingness to donate. Columbia has mandatory reporting of all donor activity, but longitudinal data on transplant outcomes is in short supply.
Nonetheless, there is a sense of transparency which may help to improve trust in the system. Recent analysis shows a minimal increase in transplant activity - however this trend was observed before the opt-out system was implemented in $2017 .^{47}$

Argentina, the largest country by geographical area in Latin America, transitioned to an "opt-out" system in 2005 (Opt-out used in inverted commas here, as this system does not follow traditional opt-out principles). ${ }^{48}$ Like most other countries, the change was prompted by low donor rates under the opt-in system. The processes associated with opt-out in Argentina at that time were unique, and relied heavily on the list of individuals whom had opted-in to donation prior to passage of the new law. Under "opt-out" legislation, families of those who had not opted-in were approached and donation would proceed if the family assured the procurement team that organ donation was the wish of the deceased. ${ }^{46}$ In terms of deceased kidney donation, this move alone reportedly led to an increase in donors from 11.7 PMP pre-transition, to 20.1 PMP post-transition. ${ }^{48}$ In spite of this increase, in July 2018, Argentina discarded its list of registered donors, and created a specific opt-out register, more in keeping with traditional opt-out systems. As yet, the impact of this change has not been quantified.

"Opt-out" in Argentina appears to have been implemented in a hybrid fashion, much like Spain. The introduction of a mechanism that facilitates donation conversations with families at the bedside, rather than an opt-out register - which would be convention, may account for the increase in deceased donor numbers. Whether the recent institution of an opt-out register has a positive, neutral or negative impact on deceased donation rates will add clarity to this argument.

The example of Brazil, which was discussed previously, illustrated the consequences of suddenly implementing a new organ donation system without appreciation for context or public sentiment. There is an important lesson to be learnt from the Brazilian experience, which is that commitment from lawmakers to rapidly amend or withdraw policies that do not have their intended consequence, is vital. The passage of legislation is notoriously slow in many developing countries, and achieving this benchmark may be a challenge.

\section{The Final Scorecard}

Independently diverting to opt-out confers no obvious advantage and doing so runs the risk of harming efforts 
to increase donor numbers. It is essential to address barriers to organ donation on several levels along with a switch in system. ${ }^{22,26,46}$ Hence, a bundle of complementary measures to bolster a new system is required. In those countries with the highest donation rates, these measures are implemented simultaneously with the new system, or incrementally thereafter. Consequently, it is all but impossible to determine the extent to which changes in donor numbers can be attributed to the new system, or the other interventions, and the affect size associated with each.

What lessons can be learnt from this extensive analysis? Firstly, there does not seem to be a single country where an increase in deceased donor numbers can be simply attributed to a change in donation system. ${ }^{13-15,22,47}$ In fact, a change in system from opt-in to opt-out, without accompanying changes addressing public education, awareness and health system structures has resulted in lower donation rates, for instance in Brazil. Moreover, those countries that are heralded as barometers of a successful opt-out system may not be so - like Spain. It is also notable that hard optout systems have not gained public acceptance and a conversation with potential donor families is still required. Hence, barriers to donation that manifest at the bedside of the deceased during this period, are not likely to fall away.

Rather, the success of organ donation policies seems to depend on clear communication, which is reinforced by extensive government buy-in and a willingness to readily respond to public sentiment should the need arise. Widespread investment in human resource infrastructure is needed at hospital level, with people capacitated to have difficult conversations with families and to identify potential donors. Technical support, with the capacity to maintain donor registers and transplant waiting lists, is also essential. Furthermore, these mechanisms need to be accountable through diligent reporting of verified data that are made public. This boosts public trust in the transplant system by demanding accountability and transparency - vital elements of successful organ donor programmes.

What conclusions can be drawn for developing countries? Past papers have argued that many developing countries, with heterogenous populations, differing literacy levels, substantial language diversity, major socio-economic challenges and a general lack of healthcare infrastructure (especially tertiary or quaternary required for transplantation) simply cannot implement ethically and legally defensible opt-out policies. It would be far better, and more economical, for these countries to work towards rendering functional the systems that are already in place. We have seen this work across the world. The difference that opt-out could make, especially in developing countries, does not seem significant enough to warrant the investment of time and resources required to support its successful implementation. Whilst the machinations of bloated legal systems take their course, perhaps over several years, there are simple things developing countries can do now to increase donor numbers.

\section{Abbreviation}

PMP, per million population.

\section{Funding}

There is no funding to report.

\section{Disclosure}

The author reports no conflicts of interest for this work.

\section{References}

1. Mshumpela CN, Etheredge HR, Fabian J, Loveland J, Botha J. Access to renal replacement therapy in South Africa- a cry for action. Transplantation. 2020;104(6):1109-1111. doi:10.1097/ TP. 000000000 0003143

2. Botha J, Conradie F, Etheredge H, et al. Living donor liver transplant from an HIV-positive mother to her HIV-negative child: opening up new therapeutic options. AIDS. 2018;32(16):F13. doi:10.1097/ QAD.0000000000002000

3. Young $\mathrm{H}$. The right to posthumous bodily integrity and implications of whose right it is. Marq Elders Adviser. 2012;14:197.

4. Stimmel, Stimmel and Roeser. Rights and obligations as to human remains and burial; 2021. Available from: https://www.stimmel-law. com/en/articles/rights-and-obligations-human-remains-and-burial. Accessed March 11, 2021.

5. Ahmad MU, Hanna A, Mohamed A-Z, et al. A systematic review of opt-out versus opt-in consent on deceased organ donation and transplantation (2006-2016). World J Surg. 2019;43(12):3161-3171. doi:10.1007/s00268-019-05118-4

6. Łuków P. Leaving gift-giving behind: the ethical status of the human body and transplant medicine. Med Health Care Philos. 2019;22 (2):221-230. doi:10.1007/s11019-018-9862-x

7. Zúñiga-Fajuri A. Increasing organ donation by presumed consent and allocation priority: Chile. B World Health Organ. 2015;93:199-202. doi:10.2471/BLT.14.139535

8. Miller J, Currie S, McGregor LM, O'Carroll RE. 'It's like being conscripted, one volunteer is better than 10 pressed men': a qualitative study into the views of people who plan to opt-out of organ donation. Br J Health Psychol. 2020;25(2):257-274. doi:10.1111/bjhp.12406

9. Yan H, Yates JF. Improving acceptability of nudges: learning from attitudes towards opt-in and opt-out policies. Judgm Decis Mak. 2019;14(1):26.

10. Veatch RM, Ross LF. Transplantation Ethics. Washington DC: Georgetown University Press; 2015.

11. Etheredge H, Penn C, Watermeyer J. Opt-in or opt-out to increase organ donation in South Africa? Appraising proposed strategies using an empirical ethics analysis. DWB. 2018;18(2):119-125. 
12. Etheredge H, Fabian J. Challenges in expanding access to dialysis in South Africa-expensive modalities, cost constraints and human rights. Healthcare. 2017;5(3):38. doi:10.3390/healthcare5030038

13. Arshad A, Anderson B, Sharif A. Comparison of organ donation and transplantation rates between opt-out and opt-in systems. Kidney Int. 2019;95(6):1453-1460. doi:10.1016/j.kint.2019.01.036

14. Matesanz R, Domínguez-Gil B. Opt-out legislations: the mysterious viability of the false. Kidney Int. 2019;95(6):1301-1303. doi:10.1016/j.kint.2019.02.028

15. Gomez-Aldana A, Tapias M, Rosselli D. Opt-out in kidney transplantation rates: the Colombian experience. Kidney Int. 2020;97 (6):1299. doi:10.1016/j.kint.2020.02.009

16. Shaw D. Presumed consent to organ donation and the family overrule. JICS. 2017;18(2):96-97. doi:10.1177/1751143717694916

17. DeRoos LJ, Marrero WJ, Tapper EB, et al. Estimated association between organ availability and presumed consent in solid organ transplant. JAMA. 2019;2(10):e1912431-e1912431.

18. Etheredge HR, Penn C, Watermeyer J. A qualitative analysis of South African health professionals' discussion on distrust and unwillingness to refer organ donors. PIT. 2018;28(2):163-169.

19. Organ Procurement and Transplantation Network. OPTN member monitoring processes; 2019. Available from: https://optn.transplant hrsa.gov/media/2937/optn_member_monitoring_processes.pdf. Accessed February 4, 2021.

20. Wald C, Russo MW, Heimbach JK, Hussain HK, Pomfret EA, Bruix J. New OPTN/UNOS policy for liver transplant allocation: standardization of liver imaging, diagnosis, classification, and reporting of hepatocellular carcinoma. Radiology. 2013;266(2):376-382. doi:10.1148/radiol.12121698

21. International Registry of Organ Donation and Trasnplantation (IRODaT). Deceased donors; 2019. Available from: https://www.iro dat.org/?p=database\#data. Accessed February 4, 2021.

22. Matesanz R, Domínguez-Gil B, Coll E, Mahíllo B, Marazuela R. How Spain reached 40 deceased organ donors per million population. Am J Transplant. 2017;17(6):1447-1454. doi:10.1111/ ajt. 14104

23. Domínguez-Gil B, Coll E, Elizalde J, et al. Expanding the donor pool through intensive care to facilitate organ donation: results of a Spanish multicenter study. Transplantation. 2017;101(8):e265-e272. doi:10.1097/TP.0000000000001701

24. Ali A, Ahmed T, Ayub A, et al. Organ donation and transplant: the Islamic perspective. Clin Transplant. 2020;34(4):e13832. doi:10.11 11/ctr. 13832

25. Ali M, Maravia U. Seven faces of a fatwa: organ transplantation and Islam. Religions. 2020;11(2):99. doi:10.3390/rel11020099

26. Chan-On C, Sarwal MM. A comprehensive analysis of the current status and unmet needs in kidney transplantation in Southeast Asia. Front Med. 2017;4:84. doi:10.3389/fmed.2017.00084

27. Martin SC, Stone AM, Scott AM, Brashers DE. Medical, personal, and social forms of uncertainty across the transplantation trajectory. Qual Health Res. 2010;20(2):182-196. doi:10.1177/1049732309 356284

28. Brown S-J. Autonomy, trust and ante-mortem interventions to facilitate organ donation. Clin Ethics. 2018;13(3):143-150. doi:10.1177/ 1477750918772264

29. Moschella M. Brain death and organ donation: a crisis of public trust. Christ Bioeth. 2018;24(2):133-150. doi:10.1093/cb/cby004

30. Gonzalez J, Garijo I, Sanchez A. Organ trafficking and migration: a bibliometric analysis of an untold story. Int $J$ Environ Res Public Health. 2020;17(9):3204. doi:10.3390/ ijerph17093204
31. Sidley P. South African doctors charged with involvement in organ trade. BMJ. 2004;329(7459):190. doi:10.1136/bmj.329.7459.190-a

32. Shaw D, Neuberger J, Murphy P. Lessons from the German organ donation scandal. JICS. 2014;14(3):200.

33. Dyer O. Journals retract 15 Chinese transplantation studies over executed prisoner concerns. BMJ. 2019;366:15220. doi:10.1136/bmj. 15220

34. Sharif A, Singh MF, Trey T, Lavee J. Organ procurement from executed prisoners in China. AJT. 2014;14(10):2246-2252.

35. Paul NW, Caplan A, Shapiro ME, Els C, Allison KC, Li H. Human rights violations in organ procurement practice in China. BMC Med Ethics. 2017;18(1):1-9. doi:10.1186/s12910-017-0169-x

36. Meszaros J, Ho C-H. Building trust and transparency? Challenges of the opt-out system and the secondary use of health data in England. Med Law Int. 2019;19(2-3):159-181. doi:10.1177/09685332198 79975

37. Reed MJ, Bruce CM, Lie KC, Harimurti K, Widodo D, Pohan HT. Re: the general public is ready for transparency about organ donation at the end of life. EMJ. 2020;37:363-369. doi:10.1136/emermed2018-208361

38. De Jager M, Wilmans C, Fabian J, Botha J, Etheredge H. Increasing deceased organ donor numbers in Johannesburg, South Africa: 18-month results of the Wits Transplant Procurement Model. SAMJ. 2019;109(9):626-631. doi:10.7196/SAMJ.2019. v109i9.14313

39. US Department of Health and Human Services. 2012 national survey of organ donation attitudes and behaviors; 2013. Available from: https://www.organdonor.gov/sites/default/files/aboutdot/files/national surveyorgandonation.pdf. Accessed March 11, 2021.

40. Loua A, Feroleto M, Sougou A, et al. A review of policies and programmes for human organ and tissue donations and transplantations, WHO African Region. Bull World Health Organ. 2020;98 (6):420. doi:10.2471/BLT.19.236992

41. Crymble K, Etheredge H, Fabian J, Gaylard P. Nurses' knowledge about and attitudes toward organ donation in state and private hospitals in Johannesburg, South Africa. South Afr J Crit Care. 2017;33 (2):52-57. doi:10.7196/322

42. Budiani DA, Karim K. The social determinants of organ trafficking: a reflection of social inequity. Soc Soc Med. 2008;4(1):48-51.

43. Jha V. End-stage renal care in developing countries: the India experience. Ren Fail. 2004;26(3):201-208. doi:10.1081/JDI120039516

44. World Health Organization. Regional Office for Africa. The state of health in the WHO African Region: an analysis of the status of health, health services and health systems in the context of the Sustainable Development Goals. World Health Organization. Regional Office for Africa; 2018. Available from: https://apps. who.int/iris/handle/10665/275292. Accessed February 4, 2021.

45. Oluyombo R, Fawale M, Ojewola R, et al. Knowledge regarding organ donation and willingness to donate among health workers in South-West Nigeria. IJOTM. 2016;7(1):19.

46. Ezaz G, Lai M. How the "Opt-In" option optimizes organ donation rates. Dig Dis Sci. 2019;64(5):1067-1069. doi:10.1007/s10620-01905483-z

47. Nino-Murcia A, Ramirez JLP, Nino-Torres L. Organ transplantation in Colombia. Transplantation. 2018;102(11):1779-1782. doi:10.1097/TP.0000000000002409

48. Saab S, Saggi SS, Akbar M, Choi G. Presumed consent: a potential tool for countries experiencing an organ donation crisis. Dig Dis Sci. 2019;64(5):1346-1355. doi:10.1007/s10620-018-5388-6 


\section{Publish your work in this journal}

Risk Management and Healthcare Policy is an international, peerreviewed, open access journal focusing on all aspects of public health, policy, and preventative measures to promote good health and improve morbidity and mortality in the population. The journal welcomes submitted papers covering original research, basic science, clinical \& epidemiological studies, reviews and evaluations, guidelines, expert opinion and commentary, case reports and extended reports. The manuscript management system is completely online and includes a very quick and fair peer-review system, which is all easy to use. Visit http://www.dovepress.com/testimonials.php to read real quotes from published authors. 